To appear in Boggio, P., Wingenbach, T.S., Comfort, W., Lira. M., \& Marrins, L. (Eds.) Social and Affective Neuroscience of Everyday Human Interaction - From Theory to Methodology.

London: Springer Nature

\title{
Molecular imaging of the human emotion circuit
}

Lauri Nummenmaa ${ }^{1,2}$, Kerttu Seppälä ${ }^{1}$ and Vesa Putkinen ${ }^{1}$

${ }^{1}$ Turku PET Centre and Turku University Hospital

${ }^{2}$ Department of Psychology, University of Turku

\section{Address correspondence to}

Lauri Nummenmaa

Turku PET Centre c/o Turku University Hospital

Kiinamyllynkatu 4-6

20520 Turku, Finland

Email:latanu@utu.fi

Tel: +358 505747933 


\begin{abstract}
Emotions modulate behavioral priorities at the central and peripheral nervous system. Understanding emotions from the perspective of specific neurotransmitter systems is critical, because of the central role of affect in multiple psychopathologies and the role of specific neuroreceptor systems as corresponding drug targets. Here we provide an integrative overview of molecular imaging studies that have targeted the human emotion circuit at the level of specific neuroreceptors and transmitters. We focus specifically on opioid, dopamine and serotonin system given their key role in modulating motivation and emotions, and discuss how they contribute to both healthy and pathological emotions.
\end{abstract}




\section{Introduction}

Emotions prepare us for action. They coordinate systemic activation patterns at multiple physiological and behavioral scales to promote survival. Most modern emotion theories consider emotions as modulatory systems interacting with both lower-order systems such as those involved in homeostasis, as well as higher-order cognitive circuits supporting decision making. Categorical models of emotions propose that evolution has specified a set of basic emotions (usually including anger, fear, disgust, happiness, sadness, and surprise but possibly also others) that support specialized survival functions [1-5]. These basic emotions are characterised by discrete neural and physiological substrates, distinctive subjective feelings (such as "I feel happy"), expressions, and a selective functionally dependent neural basis [6-10]. Much of recent neuroimaging work has aimed at mapping the functional organization of the emotion circuits in the brain using functional magnetic resonance imaging $[5,11]$, and these studies have been successful in delineating the neurobiological architecture of emotions (Figure 1).

Meta-analyses of the BOLD-fMRI data have however yielded inconsistent support for the discrete neural basis of emotions. One proposed explanation for this is the low spatial resolution of BOLDfMRI coupled with univariate analysis: if specific neural populations coding different emotions are intermixed within one voxel, their activation differences cannot be revealed by univariate techniques. In line with this view, multivariate pattern recognition studies have consistently provided support for discrete neural basis of different basic and complex emotions [8,12-14]. Even though multivariate analysis techniques improve the discriminability and specificity of data patterns across different classes or conditions [15], they cannot resolve one of the main limitations of the BOLD-EPI data - that the signal is unspecific with respect to the underlying neurotransmitter circuits.

A single voxel in an echo-planar image may contain neurons operating with a multitude of different neurotransmitters, whose net activation is reflected in the BOLD signal. Understanding emotions from the perspective of specific neurotransmitter systems is however critical, because of the central role of affect in multiple psychopathologies, and the role of specific neuroreceptor systems as drug targets. For example, the most commonly assumed working mechanism of antidepressants involve either increased neurotransmission by increasing synaptic neurotransmitter levels (such as norepinephrine or dopamine (DA)), or specific agonist effects of the targeted receptors. Thus, it is imperative to delineate not just the anatomical but also neuromolecular organization of the emotion circuits in the brain. Here we provide an overview of the molecular mechanisms of emotions, with specific focus on in vivo imaging of specific neurotransmitter and neuroreceptor studies in humans. We focus specifically on opioidergic, dopaminergic and serotonergic mechanisms, as they can be readily studied in vivo in the human brain (Figure 2).
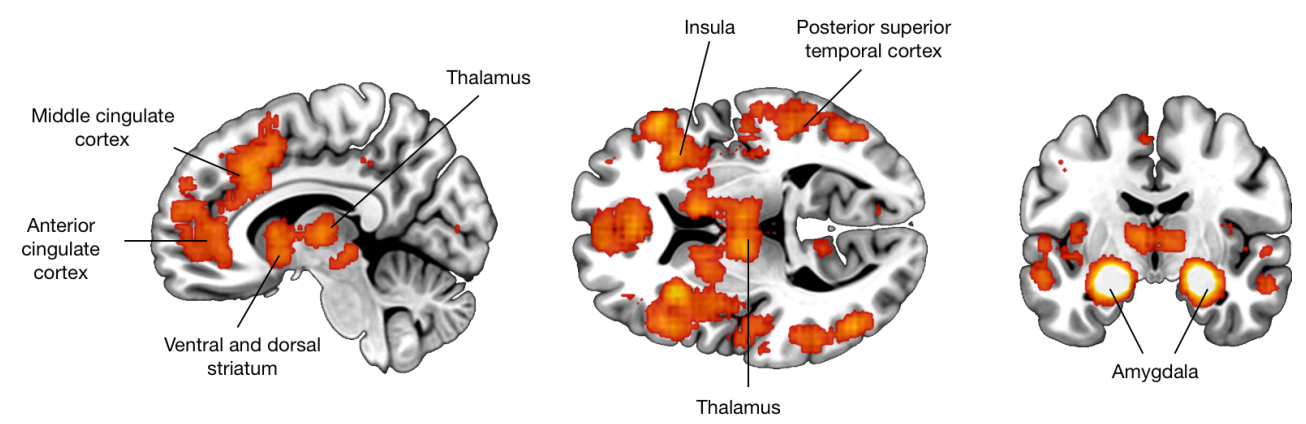

Figure 1. Statistical summary of brain regions involved in emotional processing based on the NeuroSynth database [16]. 


\section{Studying human neuroreceptor systems in vivo}

Most commonly used functional imaging (fMRI) and electromagnetic (MEG / EEG) techniques for recording brain activation do not yield any information regarding the underlying mechanisms of neurotransmission. Because pharmacological microstimulation studies are not feasible in humans, main approaches for studying emotion-related neurotransmission involve different activation, blockade and depletion studies, as well as nuclear medicine imaging techniques for direct in vivo measurements.

\section{Pharmacological activation and blockage studies}

The classical behavioral pharmacological approach involves delivering specific receptor agonists or antagonists or other pharmacologically active agents into the circulatory system, or directly into the target tissue in the case of animal studies. In humans these studies are difficult to conduct, because oral or intravenous administration leads to systemic rather than regionally specific effects, and it has been well established through animal studies that the effects of receptor agonists / antagonists can be regionally highly selective [17]. One way for overcoming this limitation is to use a pharmacological imaging approach, where functional imaging or electromagnetic recordings are performed during pharmacological treatment versus a placebo condition, which allows us to identify the brain regions where drug action leads to neural responses. However, these regional responses may still be influenced by system-level effects, and pinpointing the specific regions whose pharmacological manipulation leads to altered BOLD signal is difficult. Furthermore, these studies employ potent pharmacological agents such as morphine or dexamphetamine that require strict clinical supervision. Finally, pharmacological manipulations may lead to physiological effects that directly confound the BOLD signal, such as respiratory depression caused by opioid agonists [18], further complicating their interpretation.

\section{Monoamine depletion studies}

A complementary approach to pharmacological activation and blockage studies involves techniques that temporarily lower the functioning of monoamines such as 5-HT, DA and catecholamine, typically by blocking the synthesis or restricting the intake of amino acid precursors. The three most widely used techniques involve acute tryptophan depletion (ADT) to block 5-HT transporter synthesis by dietary restriction of the 5-HT precursor l-tryptophan. The effect is amplified by consumption of a large quantity of other amino acids that compete with tryptophan at the blood-brain barrier [19]. Phenylalanine/tyrosine depletion (APTD), in turn, targets the dopaminergic / catecholamic systems by restricting the dietary intake of its precursors phenylalanine and tyrosine. Such techniques result in specific short-term effects in distinct neurotransmitter systems rather than on general protein metabolism in the brain [20], however the interpretation of these results is complicated due to distinct system-level effects on transmitter synthesis. Nevertheless, these techniques are valuable when investigating the involvement of monoamine system function in specific mood disorders.

\section{Molecular imaging with positron emission tomography}

Functional molecular imaging using positron emission tomography (PET) is the current gold standard for in vivo molecular imaging in humans. It is based on injecting radiolabeled, biologically active molecules into the circulation. These molecules bind to specific target sites, and their unstable isotopes subsequently undergo positron emission decay. The radioisotope emits a positron - an antiparticle of an electron - which loses kinetic energy as it travels through brain tissue. After a certain degree of deceleration, the positron can interact with an electron, leading to an annihilation event producing two gamma photons (rays) moving in opposite directions. The gamma rays are recorded by the detector units of the PET camera, and on the basis of simultaneously detected gamma rays on the opposite sides of the detector ring, the location of the annihilation event can be computed. This subsequently allows reconstruction of the tracer uptake 
in the tissue. When combined with measurements of tracer input and output, these raw radioactivity counts can be transformed into biologically meaningful information such as radioligand binding at neuroreceptors.

This technique provides excellent biological resolution due to the potential for developing highly selective radioligands binding to different protein targets, and spatial resolution up to a few millimeters. Despite its high sensitivity for in vivo biomarker tracing, PET lacks capability for capturing the underlying tissue morphology; as such, this information usually needs to be acquired through separate MR or CT scans. Functional imaging of slow-acting neurotransmission is however possible [21,22], although temporal resolution is limited to tens of minutes for most neurotransmission studies. Modern integrated PET-MRI -systems [23] also allow for the simultaneous measurement of perfusion with both PET and arterial spin labelled MRI [24,25], or perfusion with MRI and neuroreceptor occupancy (PET) significantly broadening the utility of PET [26]. All in all, the PET technique is currently the most accurate and specific tool available for investigating in vivo neurotransmission in humans.

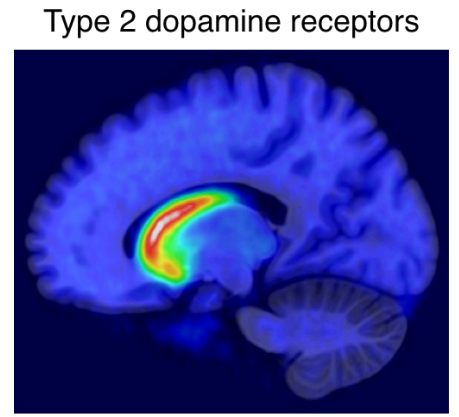

[11C]raclopride

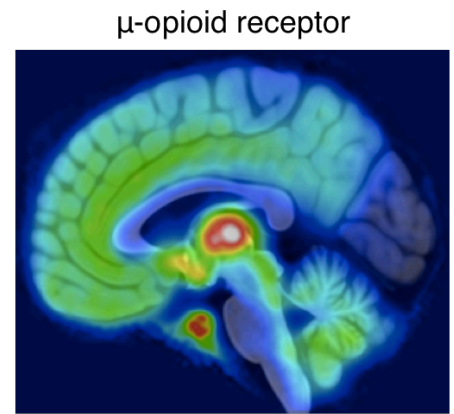

$[11 \mathrm{C}]$ carfentanil

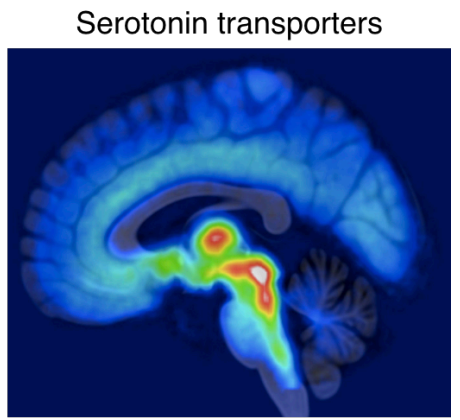

[11C]MADAM

Figure 2. Distribution of type 2 dopamine receptors, $\mu$-opioid receptors and 5-HT $1 \mathrm{~A}$ transporters measured using PET radioligands.

\section{The dopamine system}

Rewards exert a powerful influence on our behavior. Both humans and animals are motivated to obtain various rewards ranging from food and sex to social contact, and the pleasurable sensations we experience on receiving the reward further reinforce our motivation to seek and consume the same reward in the future. The monoamine neurotransmitter dopamine (DA) and its receptors D1D5 have been well-established as playing a key role in motor control and reward-related behavior and pleasure. There are multiple DA pathways in the brain that consist of neuronal projections which synthesize and release DA (Figure 3). The mesolimbic pathway projects from the ventral tegmental area (VTA) to the ventral striatum. This pathway is particularly involved in processing incentive salience, generating pleasure responses and reinforcement learning. The mesocortical pathway projecting from the VTA to the prefrontal cortex is, in turn, more involved in executive functions although it also contributes to reward processing. The nigrostriatal pathway connects substantia nigra to the striatum (putamen and caudate), and contributes critically to motion control. Finally, the tuberoinfundibular pathway connects the hypothalamus and the pituitary gland. Importantly, all the main functions of the dopamine system are also central to reward processing, and it comes as no surprise that dopamine system has been implicated as one of the primary molecular pathways for reward [27]. 


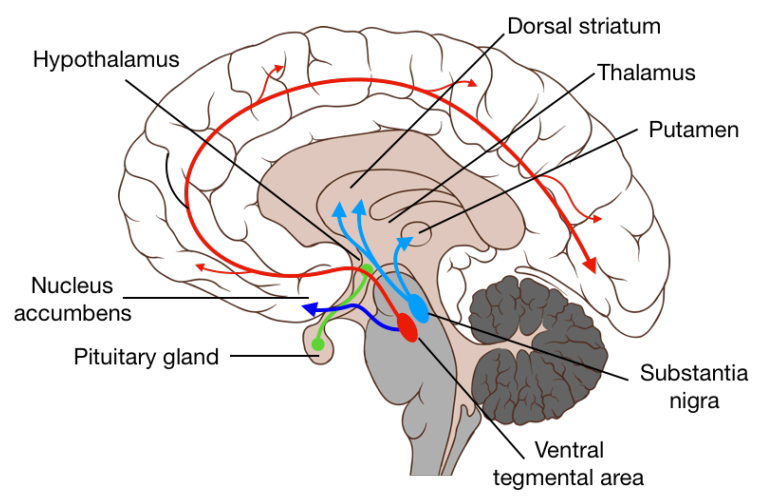

- Mesolimbic pathway $\quad$ Nigrostriatal pathway
— Mesocortical pathway $\quad$ Tuberoinfundibular pathway

Figure 3. Main dopamine pathways in the brain.

PET studies using the radioligand [11C]raclopride in humans have consistently demonstrated DA release in central pathways during reward processing. Due to the poor temporal accuracy of PET, it is exceedingly difficult to dissect the contribution of reward expectation and consumption phases to the release of DA: It is difficult to design sufficiently long ( $\sim 45 \mathrm{~min})$ tasks where rewards would be only anticipated but not delivered. As a result, studies conducted in this area mix both anticipation- and consumption-related effects. The PET analysis of DA transmission in reward has shown that feeding - one of the most salient biological rewards - triggers DA release primarily in the striatum. Because the magnitude of DA release is associated with evaluation of the subjective pleasantness of the meal, this finding has been interpreted as evidence for hedonic (rather than homeostatic) responses to feeding [28]. This is further supported by another series of studies, which measured DA release during intravenous glucose / placebo delivery, thus precluding the subjective evaluation of the reward value of the glucose, yet systemically altering the blood glucose levels simulating a postprandial state [29,30]. These studies found no differences between the glucose and placebo conditions, suggesting that alterations in circulating glucose levels are not sufficient for central DA release. Instead, the hedonic responses driven by the orosensory and chemical taste pathways appear to be crucial for the DA response triggered by feeding.

There is less evidence for DA processing of other primary reward signals, but some studies suggest that romantic [31] and maternal attachment-related rewards [32] are processed via the dopamine system in humans. However, these studies are difficult to interpret as the latter [32] reported dopamine activations in regions where $[11 \mathrm{C}]$ raclopride has either low or no specific binding and no sensitivity to even D2/D3R antagonist challenge [33], and the former was based on an individual-differences approach [31] and failed to show significant main effects of DA release across the whole group of subjects. In addition, murine models typically show a decrease in DA release in response to social contact seeking [34], rather than an increase as suggested by human PET data; this might however be due to cross-species differences. Striatal DA reward signaling has however been shown to extend beyond biologically significant rewards. For example, more "cognitive" rewards such as listening to one's favorite music [35], gambling [36] and playing video games [37] leads to striatal dopamine release. In all of these tasks the reward value is learned rather than intrinsic, suggesting that acquired reward signals are processed in comparable fashion via DA signaling as those with innate reward value. This is most clearly highlighted by data that shows that simple cognitive tasks such as task switching may trigger striatal DA release as soon as they are coupled with rewards [38].

Negative emotions also induce DA release. One study using [18F] fallypride revealed increased dopamine release in the amygdala and mediolateral frontal cortex during processing of negative 
emotional words [39], while a subsequent study using [11C] raclopride found similar effects in the caudate nucleus and putamen [40]. There are multiple possibilities for the apparently contradicting findings showing that both pleasure and displeasure can lead to DA activation. For example, it is possible that the DA response to negative stimuli reflects preparatory avoidance behavior triggered by the aversive stimulus, consistent with the role of DA release in motor responses geared towards specific behavioral patterns. This might be reflected in similar activation as the preparatory approach for rewards during pleasurable events. Finally, type-2 DA receptors (D2R) have also been linked with executive control and working memory [22], and the emotion-dependent DA activations might reflect the prediction and planning of both escape (negative emotions) and seeking and exploration responses (positive emotions).

Recent PET-fMRI fusion imaging has also tried to dissect the specific role of DA in processing different aspects of emotions, specifically the pleasure-displeasure (valence) and arousal axes. This approach is based on separate PET measurement of neuroreceptor distribution, which can then be used to predict emotion-dependent BOLD responses in subsequent fMRI experiments [41]. The logic of these experiments is to examine whether interindividual variation in the regional BOLD responses is dependent on corresponding variability in neurotransmitter availability, which would be indicative of DA involvement in the emotional processes targeted in the fMRI experiment. However, this work has failed to establish associations between D2R availability and emotionspecific BOLD responses [42] and instead suggests a key role of opioid system in modulating basic affective responses (see below).

Given the central role of dopamine in modulating motivation and reward, it is not surprising that dysregulated dopaminergic neurotransmission is the hallmark of numerous addictive disorders [43]. Human imaging studies have demonstrated that alcohol and drug dependence are associated with lowered D2R availability [44-46]. Additionally, drug-induced striatal dopamine responses are blunted in methamphetamine abusers [47]. With behavioral addictions and addiction-like behaviors the results are less clear. Animal studies on obesity suggest that striatal D2R is downregulated in the obese brain [48], while human studies have yielded mixed results with some finding lower [4951] and others unaltered [29,30,52] D2R availability in the striatum. Finally, pathological gambling is not associated with altered D2R availability [36]. However, gambling-dependent dopamine signalling is amplified in pathological gamblers versus controls [36], in contrast to the blunting effect observed in amphetamine abusers upon drug administration [47]. In sum, substance abuse appears to markedly downregulate the D2R system possibly via direct pharmacological effects, whereas behavioural addictions and addiction-like states are modulated by at least partially independent pathways.

\section{Opioid system}

Endogenous opioids are expressed widely throughout the human central nervous system (Figure 4) and numerous high-density receptor sites constitute central nodes in the human emotion circuit [53]. Among the three classes of opioid receptors $(\mu, \delta$, and $x)$, the $\mu$ receptors mediate the effects of endogenous $\beta$-endorphins, endomorphins, enkephalins, and various exogenous opioid agonists [54]. The predominant action of $\mu$-opioids in the central nervous system is inhibitory, but they can also exert excitatory effects. The neurons synthesizing $\beta$-endorphin are found in the arcuate nucleus in hypothalamus and the nucleus tractus solitarii of the medulla, which projects extensively to regions throughout the CNS. Dopamine is oftentimes considered as the primary neurotransmitter for reward processing [27]. Opioid and dopamine systems are however closely interlinked on cellular level [55], and opioids can produce reward independently of dopamine [56], likely via partially independent molecular pathways. 
Opiates are commonly used illicit drugs particularly in the US, where the lifetime prevalence of opioid use disorder exceeds $2 \%$ [57]. Such high misuse potential is attributed to the strong 'liking' responses - the pleasurable subjective experiences produced by drug consumption [58]. However, experiments with drug-naïve volunteers have not provided consistent results on opioid agonists associated with liking or pleasure. Some studies report increased pleasure upon $\mu$-receptor (MOR) agonist delivery [59-61], whereas others have not corroborated these findings [62-64]. These discrepancies likely pertain to differences in the route of administration, receptor affinity and genetically determined variation in receptor expression [65]. Some recent experiments have found that opioid agonists shift the evaluation of external stimuli, making them seem more pleasant, without necessarily directly influencing tonic subjective emotional state per se [66]. Thus, it is possible that opioid agonists primarily influence the evaluative processing of emotions, rather than directly modulating the acute subjective feeling. Consequently, opioids might alleviate stress and dysphoria by shifting the evaluation of the internal and external world towards more positive directions.

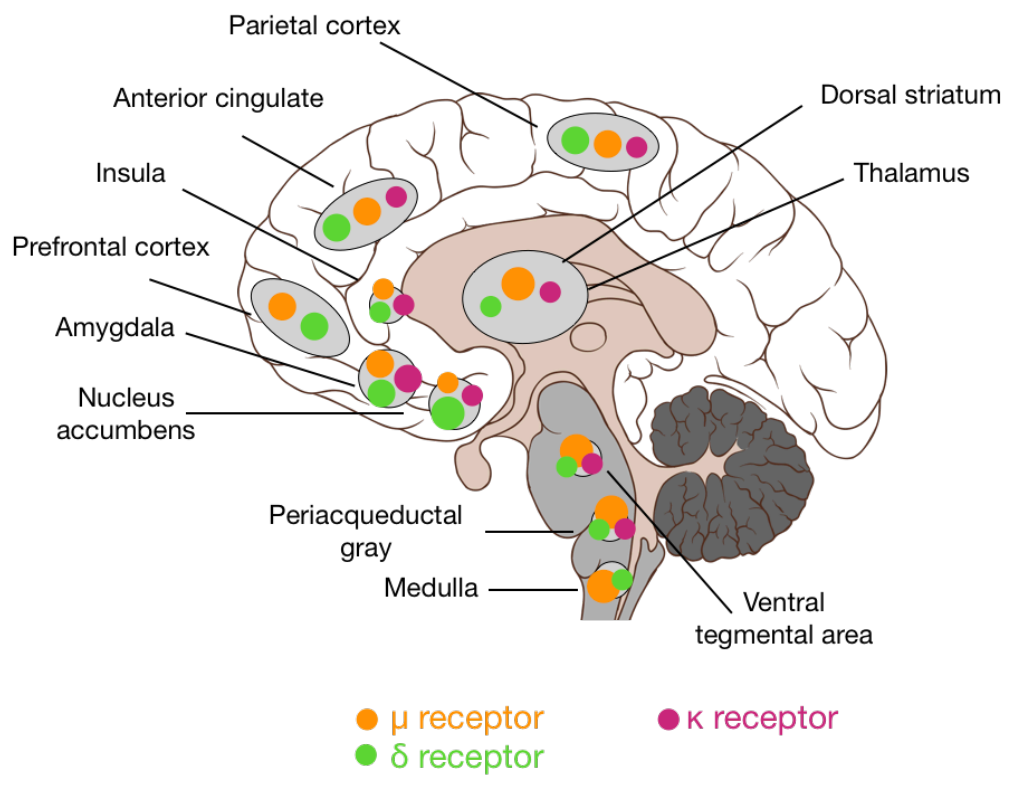

Figure 4. Organization of the human opioid system in the brain. Note that as specific opioid neuron projections cannot be established, this figure instead characterizes the relative expression of different receptor subtypes in some of the key nodes of the emotion circuit.

By contrast, molecular imaging shows that reward consumption consistently triggers endogenous opioid release. Feeding leads to increased endogenous opioid release in the reward circuit and also elsewhere in the brain $[67,68]$. However, this response is observed for both palatable and nonpalatable meals and is actually stronger for fast-metabolizing, non-appetizing liquid meals than for palatable pizza. Thus, the response is likely a combination of the low-level homeostatic pleasure of feeding after fasting which is presumably more intense in response to a quickly metabolized liquid meal, and possibly a partially independent effect of subjective hedonic responses. Corroborating evidence for the role of the opioid system in processing primary rewards comes from studies showing that pleasurable social interaction $[69,70]$ and strenuous physical exercise $[71,72]$ induce central opioid release. Similarly to dopamine, these effects extend beyond primary rewards, as for example positive moods induced by mere mental imagery induce opioid release in the amygdala [73]. Fusion imaging with PET and fMRI suggests that the opioid system governs particularly the arousal dimension of emotions. The more opioid receptors an individual has in their limbic system, the weaker their arousal-dependent BOLD responses observed in the brain's emotion circuits [42]. 
Accordingly, opioid system might act as a buffer against socioemotional stressors, alleviating the negative feelings associated with one's own or another's misfortune [41].

Whereas the general role of dopamine system in drug addictions is fairly clear-cut, the story is more nuanced with the opioid system. Alcohol dependence is associated with elevated MOR levels in the striatum [74,75], whereas cocaine dependence results in similar effects in more widespread regions, particularly cortical and cingulate areas [76]. However, chronic opiate abuse is associated with MOR downregulation [77,78]. Thus, the effects of drug abuse on MOR seem to be drugspecific. More consistent data comes from studies on obesity, that have implicated downregulated $\mu$-receptor action as one of the key pathophysiological mechanisms in the disorder $[55,68,79,80]$. These effects seem to also be specific to obesity rather than a general feature of behavioral addictions, as $\mu$-receptor downregulation is not observed in pathological gambling for example [81]. Finally, despite the centrality of the opioid system in hedonia and affective functioning, there is no clear evidence of its involvement in the pathophysiology of mood disorders. PET imaging data are limited in scope, and the existing studies have yielded conflicting evidence on opioidergic alterations in major depression [82,83]. However, one recent large-scale study shows that subclinical depressive and anxious symptoms are consistently linked with MOR system downregulation [84]. Finally, opioid system may also contribute to affective pathophysiology due to its role in governing human attachment behaviour whose disruptions are consistently linked with mood disorders [85]. This is supported by PET studies that have consistently found that insecure attachment is linked with downregulated MOR in the limbic and paralimbic regions $[86,87]$.

\section{Serotonergic system}

The monaomine neurotransmitter serotonin and its receptors $5 \mathrm{HT}_{1}-5 \mathrm{HT}_{7}$ are involved in the regulation of sleep, appetite, mood and pleasure, but it is also involved in cognitive and physiological processes. In the central nervous system serotonin is produced in the raphe nuclei in the brainstem, from where the serotonergic projections extend to the striatum and neocortex (Figure 5). Brain's serotonergic systems also play a critical role in avoidance behaviors as well as fear and anxiety. Activation of the serotonergic system is critical for avoidance behavior in rodents [88], and genetic variations in serotonin transporter (SERT) expression influence the fear circuit's responsiveness to acute threat signals in humans [89]. Thus, major categories of anxiolytic drugs also inhibit SERT.

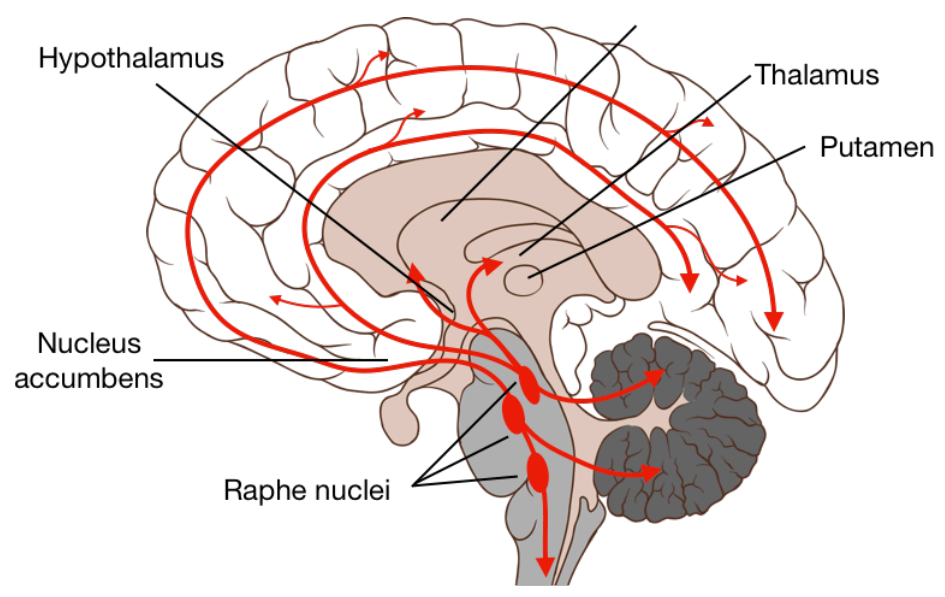

- Serotonergic pathway

Figure 5. Main serotonin pathways in the brain. 
Whereas dopamine and opioid systems are centrally involved in the pathophysiology of addictive disorders, the SERT system is consistently implicated in mood regulation and consequently in the pathogenesis of mood disorders [90]. Although initial reports on 5-HTT in mood disorders have been variable, meta-analyses suggest that serotonin transporter availability is consistently lowered in depression [91]; but see [92] and altered serotonergic neurotransmission is also considered a hallmark of depression [93]. Accordingly, most widely used and effective of antidepressants act by increasing extracellular serotonin levels. Importantly, individual differences in the expression of the serotonin transporter mediate the effects of stressful life events on the onset of depression [94]. In similar fashion, serotonin transporter availability varies seasonally, suggest that altered serotonergic function may also underlie pathophysiology of seasonal affective disorders [95].

Functional molecular imaging of the serotonergic system has been limited due to the lack of radioligands that show sensitivity to endogenous serotonin levels, essentially preventing serotonin activation studies with PET. However, fusion PET-fMRI imaging has elucidated the role of SERT in emotional processing. A number of studies indicate that the serotonergic system regulates amygdala responsiveness to facial expressions of emotions [96-99]. For instance, PET-fMRI studies have found an inverse relationship between 5-HT1A receptor density in the dorsal raphe nucleus (DRN) or HT2A density in the prefrontal cortex and the magnitude of amygdala BOLD response to emotional faces [96-98,100]. Some studies have also yielded conflicting results, with no association between 5-HT1A binding and emotional face processing [101]. For practical and economic reasons, these types of multimodal neuroimaging studies have limited statistical power (oftentimes n:s < 30), which may yield inconsistent effects in correlational designs. However, pharmacological activation studies provide corroborating evidence for serotonergic modulation of amygdala responses to threat. Multiple studies have documented that serotonin reuptake inhibitors (SSRIs) modulate amygdala reactivity to emotional facial expressions [102-105]. These effects are however not just face-specific, but extend to emotional processing in general and also to emotions derived from natural speech. The serotonin and norepinephrine receptor antagonist mirtazapine attenuates responses to unpleasant events in sensorimotor and anterior areas while modulating responses to arousing events in cortical midline structures. These effects are paralleled by increased functional connectivity between cortical midline and limbic areas during pleasant events [106], suggesting large-scale modulation of affective processing by serotonergic drugs.

From a clinical viewpoint, subjective feelings linked with the neural and autonomic emotional response are also an important facet of mood disorders. In particular, negative self-concept and increased self-focus play an important role in the pathophysiology of depression. Some studies suggest that the serotonergic system can influence how subjects interpret and process self-relevant affective information. Mirtazapine attenuates self-referential emotional processing in healthy volunteers, as manifested in decreased cortical midline activation [107]. This mechanism could underlie one form of serotonin-dependent antidepressant action. This is further evidenced in clinical trials, which show how short-term escitalopram treatment regulates self-referential processing in patients with major depressive disorder [108]. Thus, serotonergic modulation seems to occur at multiple levels of the human emotion circuit, ranging from sensory to evaluative, cognitive and self-referential processes, and the serotonergic action of antidepressants likely impacts all these levels.

\section{Conclusions}

Recent advances in nuclear medicine imaging have helped to elucidate the role of opioid, dopamine, and serotonin systems in human emotions. There is clear evidence that dopamine and opioid systems modulate hedonic processes. However, both dopaminergic and opioidergic activation is observed during negative emotions too, suggesting that they may also support general motivational 
and arousal-modulation components of emotions. At a pathophysiological level, the dopamine system is more clearly linked with substance abuse and addictive disorders, whereas opioidergic activations vary from substance to substance, with clear downregulation observed particularly in obesity. The serotonin system links more clearly with negative emotions including fear and sadness, yet outside pharmacological and clinical studies, the majority of these data come from pharmacological fMRI studies and those correlating transporter availability with BOLD-fMRI responses.

There is no clear one-to-one mapping between specific emotions or emotional behaviors and specific neurotransmitters. Obviously numerous neurotransmitters have a wide variety of roles, and their specific actions are not limited to emotional behavior. Human imaging studies are challenging to conduct, and are limited by radioligand pharmacokinetics and affinity. For the major neurotransmitter systems implicated in emotion, reliable radioligands exist for imaging serotonin, dopamine, opioid and endocannabinoid receptors and transmitters. For opioid and dopamine systems, there are also radioligands available that are sensitive to endogenous transmitter levels, whereas this has yet to be achieved for serotonin and endocannabinoid systems. In sum, targeting neurotransmitter mechanisms of emotions using PET is a powerful tool for dissecting the molecular mechanisms of emotions, further potentiated by next-generation PET-MRI devices which allow us to address the molecular specificity of emotion-related BOLD activation. 
References

1. Panksepp J: Toward a general psychobiological theory of emotions. Behavioral and Brain Sciences 1982, 5:407-422.

2. Ekman P: An argument for basic emotions. Cognition \& Emotion 1992, 6:169-200.

3. Cordaro DT, Sun R, Keltner D, Kamble S, Huddar N, McNeil G: Universals and Cultural Variations in 22 Emotional Expressions Across Five Cultures. Emotion 2018, 18:7593.

4. Cowen AS, Keltner D: Self-report captures 27 distinct categories of emotion bridged by continuous gradients. Proceedings of the National Academy of Sciences 2017.

5. Nummenmaa L, Saarimäki H: Emotions as discrete patterns of systemic activity. Neuroscience Letters 2017.

6. Tracy JL, Randles D: Four Models of Basic Emotions: A Review of Ekman and Cordaro, Izard, Levenson, and Panksepp and Watt. Emotion Review 2011, 3:397-405.

7. Nummenmaa L, Glerean E, Hari R, Hietanen JK: Bodily maps of emotions. Proceedings of the National Academy of Sciences of the United States of America 2014, 111:646-651.

8. Saarimäki H, Gotsopoulos A, Jääskeläinen IP, Lampinen J, Vuilleumier P, Hari R, Sams M, Nummenmaa L: Discrete Neural Signatures of Basic Emotions. Cerebral Cortex 2016, 6:2563-2573.

9. Kreibig SD: Autonomic nervous system activity in emotion: A review. Biological Psychology 2010, 84:394-421.

10. Nummenmaa L, Hari R, Hietanen JK, Glerean E: Maps of subjective feelings. Proceedings of the National Academy of Sciences of the United States of America 2018, 115:9198-9203.

11. Wager TD, Kang J, Johnson TD, Nichols TE, Satpute AB, Barrett LF: A Bayesian Model of Category-Specific Emotional Brain Responses. PLOS Computational Biology 2015, 11:e1004066.

12. Saarimäki H, Ejtehadian LF, Glerean E, Jääskeläinen IP, Vuilleumier P, Sams M, Nummenmaa L: Distributed affective space represents multiple emotion categories across the human brain. Social Cognitive and Affective Neuroscience 2018:nsy018-nsy018.

13. Kragel PA, Knodt AR, Hariri AR, LaBar KS: Decoding Spontaneous Emotional States in the Human Brain. PLOS Biology 2016, 14:e2000106.

14. Kragel PA, Labar KS: Multivariate neural biomarkers of emotional states are categorically distinct. Social Cognitive and Affective Neuroscience 2015, 10:1437-1448.

15. Norman KA, Polyn SM, Detre GJ, Haxby JV: Beyond mind-reading: multi-voxel pattern analysis of fMRI data. Trends in Cognitive Sciences 2006, 10:424-430.

16. Yarkoni T, Poldrack RA, Nichols TE, Van Essen DC, Wager TD: NeuroSynth: a new platform for large-scale automated synthesis of human functional neuroimaging data. Frontiers in Neuroinformatics 2011.

17. Berridge KC, Kringelbach ML: Pleasure Systems in the Brain. Neuron 2015, 86:646-664.

18. Pattinson KTS: Opioids and the control of respiration. BJA: British Journal of Anaesthesia 2008, 100:747-758.

19. Booij L, Van der Does AJW, Riedel WJ: Monoamine depletion in psychiatric and healthy populations: review. Molecular Psychiatry 2003, 8:951.

20. Booij L, Van der Does AJW, Riedel WJ: Monoamine depletion in psychiatric and healthy populations: review. Molecular Psychiatry 2003, 8:951-973.

21. Zubieta JK, Smith YR, Bueller JA, Xu YJ, Kilbourn MR, Jewett DM, Meyer CR, Koeppe RA, Stohler CS: Regional mu opioid receptor regulation of sensory and affective dimensions of pain. Science 2001, 293:311-315.

22. Backman L, Nyberg L, Soveri A, Johansson J, Andersson M, Dahlin E, Neely AS, Virta J, Laine M, Rinne JO: Effects of Working-Memory Training on Striatal Dopamine Release. Science 2011, 333:718-718. 
23. Judenhofer MS, Wehrl HF, Newport DF, Catana C, Siegel SB, Becker M, Thielscher A, Kneilling M, Lichy MP, Eichner M, et al.: Simultaneous PET-MRI: a new approach for functional and morphological imaging. Nature Medicine 2008, 14:459-465.

24. Zhang K, Herzog H, Mauler J, Filss C, Okell TW, Kops ER, Tellmann L, Fischer T, Brocke B, Sturm W, et al.: Comparison of cerebral blood flow acquired by simultaneous O15 water positron emission tomography and arterial spin labeling magnetic resonance imaging. Journal of Cerebral Blood Flow and Metabolism 2014, 34:1373-1380.

25. Heijtel DFR, Mutsaerts H, Bakker E, Schober P, Stevens MF, Petersen ET, van Berckel BNM, Majoie C, Booij J, van Osch MJP, et al.: Accuracy and precision of pseudocontinuous arterial spin labeling perfusion during baseline and hypercapnia: $\mathrm{A}$ head-to-head comparison with $\mathrm{O}-15 \mathrm{H} 2 \mathrm{O}$ positron emission tomography. Neuroimage 2014, 92:182-192.

26. Sander CY, Mandeville JB, Wey H-Y, Catana C, Hooker JM, Rosen BR: Effects of flow changes on radiotracer binding: Simultaneous measurement of neuroreceptor binding and cerebral blood flow modulation. Journal of cerebral blood flow and metabolism in press.

27. Wise RA, Rompre PP: Brain Dopamine and Reward. Annual Review of Psychology 1989, 40:191-225.

28. Small DM, Jones-Gotman M, Dagher A: Feeding-induced dopamine release in dorsal striatum correlates with meal pleasantness ratings in healthy human volunteers. Neuroimage 2003, 19:1709-1715.

29. Haltia LT, Rinne JO, Helin S, Parkkola R, Nagren K, Kaasinen V: Effects of intravenous placebo with glucose expectation on human basal ganglia dopaminergic function. Synapse 2008, 62:682-688.

30. Haltia LT, Rinne JO, Merisaari H, Maguire RP, Savontaus E, Helin S, Nagren K, Kaasinen V: Effects of intravenous glucose on dopaminergic function in the human brain in vivo. Synapse 2007, 61:748-756.

31. Takahashi K, Mizuno K, Sasaki AT, Wada Y, Tanaka M, Ishii A, Tajima K, Tsuyuguchi N, Watanabe K, Zeki S, et al.: Imaging the passionate stage of romantic love by dopamine dynamics. Front Hum Neurosci 2015, 9:191.

32. Atzil S, Touroutoglou A, Rudy T, Salcedo S, Feldman R, Hooker JM, Dickerson BC, Catana C, Barrett LF: Dopamine in the medial amygdala network mediates human bonding. Proceedings of the National Academy of Sciences 2017:201612233.

33. Svensson JE, Schain M, Plavén-Sigray P, Cervenka S, Tiger M, Nord M, Halldin C, Farde L, Lundberg J: Validity and reliability of extrastriatal [11-C] raclopride binding quantification in the living human brain. bioRxiv 2019:600080.

34. Manduca A, Campolongo P, Palmery M, Vanderschuren L, Cuomo V, Trezza V: Social play behavior, ultrasonic vocalizations and their modulation by morphine and amphetamine in Wistar and Sprague-Dawley rats. Psychopharmacology 2014, 231:16611673.

35. Salimpoor VN, Benovoy M, Larcher K, Dagher A, Zatorre RJ: Anatomically distinct dopamine release during anticipation and experience of peak emotion to music. Nature Neuroscience 2011, 14:257-U355.

36. Joutsa J, Johansson J, Niemela S, Ollikainen A, Hirvonen MM, Piepponen P, Arponen E, Alho H, Voon V, Rinne JO, et al.: Mesolimbic dopamine release is linked to symptom severity in pathological gambling. Neuroimage 2012, 60:1992-1999.

37. Koepp MJ, Gunn RN, Lawrence AD, Cunningham VJ, Dagher A, Jones T, Brooks DJ, Bench CJ, Grasby PM: Evidence for striatal dopamine release during a video game. Nature 1998, 393:266-268. 
38. Jonasson LS, Axelsson J, Riklund K, Braver TS, Ogren M, Backman L, Nyberg L: Dopamine release in nucleus accumbens during rewarded task switching measured by C-11 raclopride. Neuroimage 2014, 99:357-364.

39. Badgaiyan RD, Fischman AJ, Alpert NM: Dopamine release during human emotional processing. Neuroimage 2009, 47:2041-2045.

40. Badgaiyan RD: Dopamine is released in the striatum during human emotional processing. Neuroreport 2010, 21:1172-1176.

41. Karjalainen T, Karlsson HK, Lahnakoski JM, Glerean E, Nuutila P, Jaaskelainen IP, Hari R, Sams M, Nummenmaa L: Dissociable Roles of Cerebral mu-Opioid and Type 2 Dopamine Receptors in Vicarious Pain: A Combined PET-fMRI Study. Cereb Cortex 2017:1-10.

42. Karjalainen T, Seppala K, Glerean E, Karlsson HK, Lahnakoski JM, Nuutila P, Jaaskelainen IP, Hari R, Sams M, Nummenmaa L: Opioidergic Regulation of Emotional Arousal: A Combined PET-fMRI Study. Cerebral cortex (New York, N.Y. : 1991) 2018.

43. Volkow ND, Fowler JS, Wang GJ, Baler R, Telang F: Imaging dopamine's role in drug abuse and addiction. Neuropharmacology 2009, 56:3-8.

44. Volkow ND, Wang GJ, Fowler JS, Logan J, Hitzemann R, Ding YS, Pappas N, Shea C, Piscani K: Decreases in dopamine receptors but not in dopamine transporters in alcoholics. Alcohol Clin Exp Res 1996, 20:1594-1598.

45. Volkow ND, Chang L, Wang GJ, Fowler JS, Ding YS, Sedler M, Logan J, Franceschi D, Gatley J, Hitzemann R, et al.: Low level of brain dopamine $\mathbf{D} 2$ receptors in methamphetamine abusers: association with metabolism in the orbitofrontal cortex. Am J Psychiatry 2001, 158:2015-2021.

46. Martinez D, Saccone PA, Liu F, Slifstein M, Orlowska D, Grassetti A, Cook S, Broft A, Van Heertum R, Comer SD: Deficits in dopamine $\mathbf{D}(2)$ receptors and presynaptic dopamine in heroin dependence: commonalities and differences with other types of addiction. Biol Psychiatry 2012, 71:192-198.

47. Volkow ND, Tomasi D, Wang GJ, Logan J, Alexoff DL, Jayne M, Fowler JS, Wong C, Yin P, Du C: Stimulant-induced dopamine increases are markedly blunted in active cocaine abusers. Molecular Psychiatry 2014, 19:1037.

48. Johnson PM, Kenny PJ: Dopamine D2 receptors in addiction-like reward dysfunction and compulsive eating in obese rats. Nat Neurosci 2010, 13:635-641.

49. Wang GJ, Volkow ND, Logan J, Pappas NR, Wong CT, Zhu W, Netusil N, Fowler JS: Brain dopamine and obesity. Lancet 2001, 357:354-357.

50. de Weijer BA, van de Giessen E, van Amelsvoort TA, Boot E, Braak B, Janssen IM, van de Laar A, Fliers E, Serlie MJ, Booij J: Lower striatal dopamine D2/3 receptor availability in obese compared with non-obese subjects. EJNMMI Res 2011, 1:37.

51. Volkow ND, Wang GJ, Telang F, Fowler JS, Thanos PK, Logan J, Alexoff D, Ding YS, Wong $\mathrm{C}, \mathrm{Ma} Y$, et al.: Low dopamine striatal $\mathbf{D} 2$ receptors are associated with prefrontal metabolism in obese subjects: possible contributing factors. Neuroimage 2008, 42:1537-1543.

52. Steele KE, Prokopowicz GP, Schweitzer MA, Magunsuon TH, Lidor AO, Kuwabawa H, Kumar A, Brasic J, Wong DF: Alterations of central dopamine receptors before and after gastric bypass surgery. Obes Surg 2010, 20:369-374.

53. Kantonen T, Karjalainen T, Isojärvi J, Nuutila P, Tuisku J, Rinne J, Hietala J, Kaasinen V, Kalliokoski $\mathrm{K}$, Scheinin $\mathrm{H}$, et al.: Interindividual variability and lateralization of $\boldsymbol{\mu}$ opioid receptors in the human brain. NeuroImage 2020.

54. Henriksen G, Willoch F: Imaging of opioid receptors in the central nervous system. Brain 2008, 131:1171-1196. 
55. Tuominen L, Tuulari J, Karlsson H, Hirvonen J, Helina S, Salminen P, Parkkola R, Hietala J, Nuutila P, Nummenmaa L: Aberrant mesolimbic dopamine-opiate interaction in obesity. Neuroimage 2015, 122:80-86.

56. Hnasko TS, Sotak BN, Palmiter RD: Morphine reward in dopamine-deficient mice. Nature 2005, 438:854-857.

57. Grant BF, Saha TD, Ruan WJ, Goldstein RB, Chou SP, Jung J, Zhang H, Smith SM, Pickering RP, Huang B, et al.: Epidemiology of DSM-5 Drug Use Disorder: Results From the National Epidemiologic Survey on Alcohol and Related Conditions-III. JAMA Psychiatry 2016, 73:39-47.

58. Comer SD, Zacny JP, Dworkin RH, Turk DC, Bigelow GE, Foltin RW, Jasinski DR, Sellers EM, Adams EH, Balster R, et al.: Core outcome measures for opioid abuse liability laboratory assessment studies in humans: IMMPACT recommendations. Pain 2012, 153:2315-2324.

59. Zacny JP, Gutierrez S: Characterizing the subjective, psychomotor, and physiological effects of oral oxycodone in non-drug-abusing volunteers. Psychopharmacology (Berl) 2003, 170:242-254.

60. Zacny JP, Gutierrez S: Within-subject comparison of the psychopharmacological profiles of oral hydrocodone and oxycodone combination products in non-drugabusing volunteers. Drug Alcohol Depend 2009, 101:107-114.

61. Riley JL, Hastie BA, Glover TL, Fillingim RB, Staud R, Campbell CM: Cognitive-affective and somatic side effects of morphine and pentazocine: side-effect profiles in healthy adults. Pain Med 2010, 11:195-206.

62. Ipser JC, Terburg D, Syal S, Phillips N, Solms M, Panksepp J, Malcolm-Smith S, Thomas K, Stein DJ, van Honk J: Reduced fear-recognition sensitivity following acute buprenorphine administration in healthy volunteers. Psychoneuroendocrinology 2013, 38:166-170.

63. Tedeschi G, Smith AT, Richens A: Effect of meptazinol and ethanol on human psychomotor performance and mood ratings. Human Toxicology 1984, 3:37-43.

64. Lasagna L, Vonfelsinger JM, Beecher HK: Drug-induced mood changes in Man. 1. Observations on healthy subjects, chronically ill patients, and postaddicts. . JamaJournal of the American Medical Association 1955, 157:1006-1020.

65. Levran O, Yuferov V, Kreek MJ: The genetics of the opioid system and specific drug addictions. Hum Genet 2012, 131:823-842.

66. Heiskanen T, Leppä M, Suvilehto J, Akural E, Larinkoski T, Jääskeläinen IP, Sams M, Nummenmaa L, Kalso E: The opioid agonist remifentanil increases subjective pleasure during emotional stimulation. British Journal of Anaesthesiology in press.

67. Tuulari JJ, Tuominen L, de Boer FE, Hirvonen J, Helin S, Nuutila P, Nummenmaa L: Feeding Releases Endogenous Opioids in Humans. Journal of Neuroscience 2017, 37:8284-8291.

68. Burghardt PR, Rothberg AE, Dykhuis KE, Burant CF, Zubieta JK: Endogenous Opioid Mechanisms Are Implicated in Obesity and Weight Loss in Humans. Journal of Clinical Endocrinology \& Metabolism 2015, 100:3193-3201.

69. Hsu DT, Sanford BJ, Meyers KK, Love TM, Hazlett KE, Wang H, Ni L, Walker SJ, Mickey BJ, Korycinski ST, et al.: Response of the mu-opioid system to social rejection and acceptance. Molecular Psychiatry 2013, 18:1211-1217.

70. Manninen S, Tuominen L, Dunbar RIM, Karjalainen T, Hirvonen J, Arponen E, Jääskeläinen IP, Hari R, Sams M, Nummenmaa L: Social laughter triggers endogenous opioid release in humans. The Journal of Neuroscience 2017, 37:6125-6131.

71. Boecker H, Sprenger T, Spilker ME, Henriksen G, Koppenhoefer M, Wagner KJ, Valet M, Berthele A, Tolle TR: The Runner's High: Opioidergic Mechanisms in the Human Brain. Cerebral Cortex 2008, 18:2523-2531. 
72. Saanijoki T, Tuominen L, Tuulari JJ, Nummenmaa L, Arponen E, Kalliokoski K, Hirvonen J: Opioid Release after High-Intensity Interval Training in Healthy Human Subjects. Neuropsychopharmacology 2017.

73. Koepp MJ, Hammers A, Lawrence AD, Asselin MC, Grasby PM, Bench CJ: Evidence for endogenous opioid release in the amygdala during positive emotion. Neuroimage 2009, 44:252-256.

74. Heinz A, Reimold M, Wrase J, Hermann D, Croissant B, Mundle G, Dohmen BM, Braus DF, Schumann G, Machulla HJ, et al.: Correlation of stable elevations in striatal muopioid receptor availability in detoxified alcoholic patients with alcohol craving: a positron emission tomography study using carbon 11-labeled carfentanil. Arch Gen Psychiatry 2005, 62:57-64.

75. Weerts EM, Wand GS, Kuwabara H, Munro CA, Dannals RF, Hilton J, Frost JJ, McCaul ME: Positron emission tomography imaging of mu- and delta-opioid receptor binding in alcohol-dependent and healthy control subjects. Alcohol Clin Exp Res 2011, 35:2162-2173.

76. Gorelick DA, Kim YK, Bencherif B, Boyd SJ, Nelson R, Copersino M, Endres CJ, Dannals RF, Frost JJ: Imaging brain mu-opioid receptors in abstinent cocaine users: time course and relation to cocaine craving. Biol Psychiatry 2005, 57:1573-1582.

77. Koch T, Hollt V: Role of receptor internalization in opioid tolerance and dependence. Pharmacol Ther 2008, 117:199-206.

78. Whistler JL: Examining the role of mu opioid receptor endocytosis in the beneficial and side-effects of prolonged opioid use: from a symposium on new concepts in mu-opioid pharmacology. Drug Alcohol Depend 2012, 121:189-204.

79. Karlsson HK, Tuominen L, Tuulari JJ, Hirvonen J, Honka H, Parkkola R, Helin S, Salminen P, Nuutila P, Nummenmaa L: Weight loss after bariatric surgery normalizes brain opioid receptors in morbid obesity. Molecular Psychiatry 2016, 21:1057-1062.

80. Karlsson HK, Tuominen L, Tuulari JJ, Hirvonen J, Parkkola R, Helin S, Salminen P, Nuutila P, Nummenmaa L: Obesity Is Associated with Decreased mu-Opioid But Unaltered Dopamine D-2 Receptor Availability in the Brain. Journal of Neuroscience 2015, 35:3959-3965.

81. Majuri J, Joutsa J, Johansson J, Voon V, Alakurtti K, Parkkola R, Lahti T, Alho H, Hirvonen J, Arponen E, et al.: Dopamine and Opioid Neurotransmission in Behavioral Addictions: A Comparative PET Study in Pathological Gambling and Binge Eating. Neuropsychopharmacology 2016.

82. Kennedy SE, Koeppe RA, Young EA, Zubieta JK: Dysregulation of endogenous opioid emotion regulation circuitry in major depression in women. Archives of General Psychiatry 2006, 63:1199-1208.

83. Hsu DT, Sanford BJ, Meyers KK, Love TM, Hazlett KE, Walker SJ, Mickey BJ, Koeppe RA, Langenecker SA, Zubieta JK: It still hurts: altered endogenous opioid activity in the brain during social rejection and acceptance in major depressive disorder. Molecular Psychiatry 2015, 20:193-200.

84. Nummenmaa L, Karjalainen T, Isojärvi J, Kantonen T, Tuisku J, Kaasinen V, Joutsa J, Nuutila P, Kalliokoski K, Hirvonen J, et al.: Lowered endogenous mu-opioid receptor availability in subclinical depression and anxiety. Neuropsychopharmacology 2020.

85. Mikulincer M, Shaver PR: An attachment perspective on psychopathology. World Psychiatry 2012, 11:11-15.

86. Turtonen O, Saarinen A, Nummenmaa L, Tuominen L, Tikka M, Armio R-L, Hautamäki A, H. L, Raitakari O, Keltikangas-Jarvinen L, et al.: Adult attachment system links with brain $\mu$-opioid receptor availability in vivo. Biological Psychiatry in press.

87. Nummenmaa L, Manninen S, Tuominen L, Hirvonen J, Kalliokoski KK, Nuutila P, Jääskeläinen IP, Hari R, Dunbar RIM, Sams M: Adult attachment style Is associated 
with cerebral $\mu$-opioid receptor availability in humans. Human Brain Mapping 2015, 36:3621-3628.

88. Deakin JF, Graeff FG: 5-HT and mechanisms of defence. Journal of psychopharmacology (Oxford, England) 1991, 5:305-315.

89. Hariri AR, Mattay VS, Tessitore A, Kolachana B, Fera F, Goldman D, Egan MF, Weinberger DR: Serotonin transporter genetic variation and the response of the human amygdala. Science 2002, 297:400-403.

90. Mann JJ: Role of the Serotonergic System in the Pathogenesis of Major Depression and Suicidal Behavior. Neuropsychopharmacology 1999, 21:99S-105S.

91. Ichimiya T, Suhara T, Sudo Y, Okubo Y, Nakayama K, Nankai M, Inoue M, Yasuno F, Takano A, Maeda J, et al:: Serotonin transporter binding in patients with mood disorders: a PET study with [11C](+)McN5652. Biological Psychiatry 2002, 51:715-722.

92. Andrews PW, Bharwani A, Lee KR, Fox M, Thomson JA: Is serotonin an upper or a downer? The evolution of the serotonergic system and its role in depression and the antidepressant response. Neuroscience \& Biobehavioral Reviews 2015, 51:164-188.

93. Drevets WC, Frank E, Price JC, Kupfer DJ, Holt D, Greer PJ, Huang Y, Gautier C, Mathis C: Pet imaging of serotonin 1A receptor binding in depression. Biological Psychiatry 1999, 46:1375-1387.

94. Risch N, Herrell R, Lehner T, Liang KY, Eaves L, Hoh J, Griem A, Kovacs M, Ott J, Merikangas KR: Interaction Between the Serotonin Transporter Gene (5HTTLPR), Stressful Life Events, and Risk of Depression A Meta-analysis. JamaJournal of the American Medical Association 2009, 301:2462-2471.

95. Praschak-Rieder N, Willeit M, Wilson AA, Houle S, Meyer JH: SEasonal variation in human brain serotonin transporter binding. Archives of General Psychiatry 2008, 65:10721078.

96. Fisher PM, Meltzer CC, Price JC, Coleman RL, Ziolko SK, Becker C, Moses-Kolko EL, Berga SL, Hariri AR: Medial Prefrontal Cortex 5-HT2A Density Is Correlated with Amygdala Reactivity, Response Habituation, and Functional Coupling. Cerebral Cortex 2009, 19:2499-2507.

97. Fisher PM, Meltzer CC, Ziolko SK, Price JC, Moses-Kolko EL, Berga SL, Hariri AR: Capacity for 5-HT 1A -mediated autoregulation predicts amygdala reactivity. Nature Neuroscience 2006, 9:1362.

98. Selvaraj S, Mouchlianitis E, Faulkner P, Turkheimer F, Cowen PJ, Roiser JP, Howes O:

Presynaptic Serotoninergic Regulation of Emotional Processing: A Multimodal Brain Imaging Study. Biological Psychiatry 2015, 78:563-571.

99. Rhodes RA, Murthy NV, Dresner MA, Selvaraj S, Stavrakakis N, Babar S, Cowen PJ, Grasby PM: Human 5-HT Transporter Availability Predicts Amygdala Reactivity In Vivo. Journal of Neuroscience 2007, 27:9233-9237.

100. Fisher PM, Price JC, Meltzer CC, Moses-Kolko EL, Becker C, Berga SL, Hariri AR: Medial prefrontal cortex serotonin $1 \mathrm{~A}$ and $2 \mathrm{~A}$ receptor binding interacts to predict threatrelated amygdala reactivity. Biology of Mood \& Anxiety Disorders 2011, 1:2.

101. Kranz GS, Hahn A, Kraus C, Spies M, Pichler V, Jungwirth J, Mitterhauser M, Wadsak W, Windischberger C, Kasper S, et al.: Probing the association between serotonin-1A autoreceptor binding and amygdala reactivity in healthy volunteers. NeuroImage 2018, 171:1-5.

102. Anderson IM, Del-Ben CM, Mckie S, Richardson P, Williams SR, Elliott R, Deakin JFW: Citalopram modulation of neuronal responses to aversive face emotions: a functional MRI study. Neuroreport 2007, 18:1351-1355.

103. Bigos KL, Pollock BG, Aizenstein HJ, Fisher PM, Bies RR, Hariri AR: Acute 5-HT

Reuptake Blockade Potentiates Human Amygdala Reactivity.

Neuropsychopharmacology 2008, 33:3221-3225. 
104. Harmer CJ, Mackay CE, Reid CB, Cowen PJ, Goodwin GM: Antidepressant Drug Treatment Modifies the Neural Processing of Nonconscious Threat Cues. Biological Psychiatry 2006, 59:816-820.

105. Murphy SE, Norbury R, O'Sullivan U, Cowen PJ, Harmer CJ: Effect of a single dose of citalopram on amygdala response to emotional faces. The British Journal of Psychiatry 2009, 194:535-540.

106. Komulainen E, Glerean E, Meskanen K, Heikkila R, Nummenmaa L, Raij TT, Lahti J, Jylha $\mathrm{P}$, Melartin T, Isometsa E, et al.: Single dose of mirtazapine modulates whole-brain functional connectivity during emotional narrative processing. Psychiatry ResearchNeuroimaging 2017, 263:61-69.

107. Komulainen E, Heikkila R, Meskanen K, Raij TT, Nummenmaa L, Lahti J, Jylha P, Melartin T, Harmer CJ, Isometsa E, et al.: A single dose of mirtazapine attenuates neural responses to self-referential processing. Journal of Psychopharmacology 2016, 30:23-32.

108. Komulainen E, Heikkila R, Nummenmaa L, Raij TT, Harmer CJ, Isometsa E, Ekelund J:

Short-term escitalopram treatment normalizes aberrant self-referential processing in major depressive disorder. Journal of Affective Disorders 2018, 236:222-229. 